Published in "Cell Calcium 74(): 94-101, 2018"

which should be cited to refer to this work.

\title{
Characterization and potential roles of calretinin in rodent spermatozoa
}

\author{
Cindy Dressen ${ }^{\mathrm{a}, *}$, Beat Schwaller ${ }^{\mathrm{b}}$, Grégory Vegh ${ }^{\mathrm{a}}$, Fabienne Leleux ${ }^{\mathrm{a}}$, David Gall ${ }^{\mathrm{a}}$, \\ Philippe Lebrun ${ }^{a}$, Pascale Lybaert ${ }^{\mathrm{a}, *}$ \\ ${ }^{a}$ Laboratory of Physiology and Pharmacology, Faculty of Medicine, Université Libre de Bruxelles, Brussels, Belgium \\ ${ }^{\mathrm{b}}$ Anatomy, Department of Medicine, University of Fribourg, Fribourg, Switzerland
}

\section{A R T I C L E I N F O}

\section{Keywords:}

Calretinin

Spermatozoa

Acrosome reaction

Motility

Fertility

\begin{abstract}
A B S T R A C T
Calretinin has been detected in various excitable cells but the presence and putative roles of such a calciumbinding protein has never been characterized in sperm.

Epididymal spermatozoa were collected from C57Bl6 (wild-type, WT) or calretinin knockout $\left(C R^{-/-}\right.$) mice and Wistar rats. A specific staining for calretinin was detected by immunofluorescence in the principal piece of the flagellum, both in WT mouse and rat spermatozoa. Western blots confirmed the expression of calretinin in rat and WT spermatozoa as well as its absence in $C R^{-/-}$mice.

No significant difference was observed in the spontaneous acrosome reaction between WT and $C R^{-/-}$sperm. The addition of the calcium-ionophore A-23187, Thapsigargin or Progesterone to WT or $C R^{-/-}$incubated spermatozoa induced increases in the acrosome reaction but the stimulatory effects were identical in both genotypes. Motility measurements assessed by computer-assisted sperm analysis indicated that, under basal nonstimulatory conditions, $\mathrm{CR}^{-/-}$sperm exhibited a lower curvilinear velocity and a smaller lateral head movement amplitude, although no difference was observed for the beat cross frequency. After incubation with $25 \mathrm{mM}$ $\mathrm{NH}_{4} \mathrm{Cl}$, the curvilinear velocity, the amplitude of the lateral head movement and the hyperactivation were increased, while the beat cross frequency was decreased, in both genotypes.

Evaluation of the in vivo fertility potential indicated that the $C R^{-/-}$litter sizes were clearly reduced compared to the WT litter sizes.

Our study describes, for the first time, the expression of calretinin in sperm. These data extend the potential implication of calcium-binding proteins in the sperm calcium-signaling cascade and bring new insights into the understanding of sperm physiology.
\end{abstract}

\section{Introduction}

In the testis, spermatogenesis produces differentiated sperm cells yet unable to move and to interact with the oocytes. A maturation of the sperm cells is required in order to promote the fertilization process [1] Although this maturation process is initiated in the epididymis [2], the immature spermatozoa need to sojourn in the female genital tract to undergo structural and biochemical changes essential for fertilization. This process described as "capacitation" leads to the development of a hyperactivated motility and the ability for the spermatozoa to carry out the acrosome reaction $[3,4]$. Both the hyperactivation and the acrosome reaction are physiological processes highly dependent on the sperm cell intracellular calcium concentration. Spatiotemporal regulation of the calcium concentration in the sperm cell is therefore, like in many other cells, of uttermost importance. A number of channels including the sperm specific CatSper channel have been described and their role is better and better characterized [5,6]. The endoplasmic reticulum and the mitochondria are known to actively sequestrate $\mathrm{Ca}^{2+}$ but these organelles are lacking or present only in limited amount in sperm cells. Intracellular calcium stocks have been demonstrated in the acrosomal vesicle and the redundant nuclear envelope; however their possible implication in calcium release and the processes they might control is still unclear $[7,8]$.

The perfect timing and localization requires a high level of organization of molecular structures governing calcium signaling in the acrosome and the principal piece [9]. Such calcium signaling domains

Abbreviations: ALH, amplitude of the lateral head movement; BCF, beat cross frequency; BSA, bovine serum albumin; C.A.S.A., computer assisted sperm analysis; CR, calretinin; CR ${ }^{-/-}$ calretinin knock-out; DAPI, 2-(4-amidinophenyl)-1H -indole-6-carboxamidine; DMSO, dimethyl sulfoxide; HEPES, 2-[4-(2-hydroxyethyl)piperazin-1-yl] ethanesulfonic acid; HRP, horseradish peroxidase; IgG, immunoglobulins G; PNA-FITC, fluorescein isothiocyanate-labelled peanut agglutinin; PBS, phosphate buffered saline solution; SDS, sodium dodecyl sulfate; TBS, tris buffered saline solution; TBS-T, tris-buffered saline solution-tween; VCL, curvilinear velocity; WT, wild-type

* Corresponding authors.

E-mail addresses: cdressen@ulb.ac.be (C. Dressen), plybaert@ulb.ac.be (P. Lybaert). 
have recently been demonstrated in the principal piece [9]. The organization of these complexes is driven by CatSper and associates CatSper to signaling molecules such as CaMKII, calcineurin and caveolin-1. These CatSper calcium domains are involved in the complex phosphorylation processes occurring during capacitation [9]. Moreover, calmodulin, a well-known sensor/adaptor calcium-binding protein, is detected in the entire flagella except for the fibrous sheath region [9]. Despite the importance of a precise regulation of the intracellular calcium concentration in sperm, the presence and putative roles of calcium-binding proteins remain poorly characterized in these cells [10-14].

Calcium-binding proteins include several large families of proteins. The largest subfamily comprises the EF-hand calcium-binding proteins, which are recognized by the presence of EF-hand domains [15]. Such a structure consists of a helix-loop-helix motif comprising a loop sequence of mostly 12 well-conserved amino-acid residues enabling binding of calcium ions with high affinity [15]. Two major functional roles have been ascribed to the EF-hand family members. Some EF-hand calcium-binding proteins are considered as playing a role as "calcium sensors", whilst others are assumed to operate as "calcium buffers". However, no strict physiological differentiation can be made between both groups [16].

The aim of the present study was to ascertain the presence and potential roles of calretinin in murine sperm. This EF-hand calciumbinding protein was previously depicted as "calcium buffer" [16,17], whereas more recent studies tended to assign additional "calcium sensor" functions to the protein [18].

The expression and role of calretinin was studied by comparing wild-type and calretinin knockout mice. A subfertility was observed in this knockout model. The presence of calretinin was assessed by indirect immunofluorescence and Western blot analysis. The potential roles of calretinin were investigated by evaluating two major calciumdependent physiological processes involved in fertilisation, i.e. the modification of motility parameters (hyperactivation) and the acrosome reaction.

\section{Materials and methods}

\subsection{Animals}

Adult Wistar rats (3-6 months old) and adult C57Bl/6 mice (3-5 months old) were purchased from Charles River Laboratories (France). Calretinin knockout $\left(C R^{-/-}\right)$mice were generated on a mixed 129/Ola x C57Bl/6 genetic background, as described previously [19]. $C R^{-/-}$ mice were backcrossed into the $\mathrm{C} 57 \mathrm{Bl} / 6$ genetic background with a minimum of 10 generations so that $\mathrm{C} 57 \mathrm{Bl} / 6$ mice can be considered as control mice (wild-type, WT). All experiments were carried out comparing WT with $C R^{-/-}$mice. Mice and rats were housed in a climatecontrolled room with $12 \mathrm{~h}$ light $-12 \mathrm{~h}$ dark periods. Animals were fed with a standard rodent diet and received water ad libitum. The animals were euthanized by cervical dislocation (mice) or concussion followed by decapitation (rats). The laboratory animal care and experimental protocols (CEBEA n : $494 \mathrm{~N}, 495 \mathrm{~N}$ ) were approved by the "Ethical and Animal Welfare Committee" of the Université libre de Bruxelles.

\subsection{Tissues preparation and sperm collection}

The epididymides were dissected free and put into a modified KrebsRinger medium $\left(\mathrm{NaCl} 94.6 \mathrm{mM}, \mathrm{KCl} 4.78 \mathrm{mM}, \mathrm{MgSO}_{4} 1.19 \mathrm{mM}\right.$, Na Lactate $21.58 \mathrm{mM}$, Na Pyruvate $0.5 \mathrm{mM}, \mathrm{NaHCO}_{3} 25.07 \mathrm{mM}, \mathrm{CaCl}_{2}$ $1.71 \mathrm{mM}, \mathrm{KH}_{2} \mathrm{PO}_{4} 1.19 \mathrm{mM}$, D-glucose $5.56 \mathrm{mM}$, bovine serum albumin (BSA) $4 \mathrm{mg} / \mathrm{ml}, \mathrm{pH}$ 7.4). For non-capacitating conditions, the same medium was used, by replacing $\mathrm{NaHCO}_{3}$ by HEPES. The two caudae were separated from fat tissue under a binocular microscope and transferred to $3.5 \mathrm{ml}$ of the same medium. Incisions were performed on the caudae to allow spermatozoa to swim out. Spermatozoa were collected after $15 \mathrm{~min}$ incubation at $36^{\circ} \mathrm{C}$ in a $\mathrm{CO}_{2}$ incubator.

Cerebella were dissected and fixed in a solution of formalin $10 \%$ (v/ v) diluted in phosphate buffered saline solution (PBS: $\mathrm{NaH}_{2} \mathrm{PO}_{4} 3.3 \mathrm{mM}$, $\mathrm{Na}_{2} \mathrm{HPO}_{4} 6.7 \mathrm{mM}, \mathrm{NaCl} 145 \mathrm{mM}, \mathrm{pH}$ 7.4). Tissues were dehydrated by an automated process (Histokinette TP1020, Leica Microsystems, Belgium) and included in paraffin. Tissue sections ( $3 \mu \mathrm{m})$ were obtained with a microtome (RM 2245, Leica Microsystems, Belgium) and placed onto histological glass slides.

\subsection{Indirect immunofluorescence}

Five hundred microliters were collected from the sperm sample, transferred to microcentrifuge tubes and centrifuged for $5 \mathrm{~min}$ at $500 \times g$. The supernatant was discarded and $200 \mu \mathrm{l}$ PBS was added to resuspend the sperm pellet. Twenty microliters of sperm preparation was disposed onto a glass slide and spread with a glass pipette. The slides were dried at room temperature and fixed in cold absolute methanol for $15 \mathrm{~min}$ at $-20^{\circ} \mathrm{C}$. Sperm smears were used immediately or stored at $-20^{\circ} \mathrm{C}$ until used for immunofluorescence assays. Cerebellum paraffin sections were deparaffinized in toluene and rehydrated in graded ethanol and propanol solutions.

Rehydrated paraffin sections, as well as sperm smears, were rinsed twice for $5 \mathrm{~min}$ in PBS and were blocked for nonspecific reactions by incubation with normal horse serum $10 \%$ (S-2000, Vector Laboratories, Belgium) diluted in PBS. The slides were then incubated overnight at $4{ }^{\circ} \mathrm{C}$ with the polyclonal rabbit antibody raised against calretinin (214 102 , Synaptic Systems, Germany). The primary antibody was used at a dilution of 1:200 in PBS. A pre-incubation of the primary antibody was performed with the purified calretinin protein $(5 \mu \mathrm{g}$ of protein $/ 1 \mu \mathrm{l}$ of antibody serum; 214-1 P, Synaptic Systems, Germany) or calbindin D$28 \mathrm{k}$ protein $(5 \mu \mathrm{g}$ of protein $/ 1 \mu \mathrm{l}$ of antibody serum; $214-0 \mathrm{P}$, Synaptic Systems, Germany) and was used to confirm the antibody specificity. Purified non-immune rabbit immunoglobulins (IgG) were used as negative control. Slides were further rinsed twice for $5 \mathrm{~min}$ in PBS and incubated with the secondary antibody (1:200, Cy3-conjugated donkey anti-rabbit antibody, Jackson ImmunoResearch Laboratories, UnitedKingdom) diluted in PBS, for $45 \mathrm{~min}$ at room temperature. The sperm acrosome was counterstained with a fluorescein-labelled lectin Arachis hypogaea (peanut) (PNA-FITC, FL-1071, Vector Laboratories, Belgium; $15 \mu \mathrm{g} / \mu \mathrm{l}$ diluted in PBS) following a procedure described previously [22]. The nuclei were counterstained with DAPI already present in the mounting medium (Prolong Gold Antifade Reagent with DAPI, Invitrogen, Belgium).

In another series of experiments, polyclonal rabbit anti-calretinin antibodies from Swant (CR 7696, Swant, Switzerland) and from Bioprime (Bioprime CA520, Biologo, Germany) were tested. All experiments were repeated at least on 3 different WT and $C R^{-1-}$ mice and rats.

\subsection{Proteins extraction and Western blotting}

Cerebella were dissected, snap frozen in liquid $\mathrm{N}_{2}$ and ground to a powder with a mortar and a pestle. Total protein extracts were prepared by the addition of Laemmli buffer (glycerol $10 \%$, Tris- $\mathrm{HCl} 62.5 \mathrm{mM}$, SDS $2 \%$, beta-Mercaptoethanol $5 \%, \mathrm{pH} 6.8$ ) [20] to the samples. Spermatozoa were collected from the caudae epididymides by swim-out in a gassed modified Krebs-Ringer medium without BSA. After sample centrifugation at $500 \mathrm{x} \mathrm{g}$ for $5 \mathrm{~min}$, the supernatant was removed and the pellet was homogenised in Laemmli buffer $(v / v)$ to lyse the spermatozoa. A protease inhibitor cocktail (HaltTM Protease Inhibitor Cocktail, Thermo Scientific Pierce, Belgium) was added to the proteins extracts. The samples were boiled for $5 \mathrm{~min}$ and centrifuged at $16,000 \times g$ for $15 \mathrm{~min}$ at $4^{\circ} \mathrm{C}$. The supernatant was collected and stored at $-80^{\circ} \mathrm{C}$. The concentrations of the total protein extracts were measured with a filter paper dye-binding assay [21].

Total protein extracts were diluted, if needed, with Laemmli buffer 
and $0.001 \%$ of Bromophenol blue was added. The proteins $(1 \mu \mathrm{g}$ of cerebellum protein extract, $25 \mu \mathrm{g}$ of sperm protein extract) and a standard molecular weight marker (Precision Plus Protein, Bio-Rad, Belgium) were loaded on a $12 \%$ poly-acrylamide gel. After SDS-PAGE electrophoresis using a Mini-Protean 3 Electrophoresis Cell (Bio-Rad Laboratories, Belgium), proteins were transferred onto nitrocellulose membranes (Nitrocellulose Membranes $0.45 \mu \mathrm{m}$, Bio-Rad, Belgium). The membranes were blocked for $1 \mathrm{~h}$ in TBS-T [Tris buffered saline solution (TBS: NaCl $100 \mathrm{mM}$, Tris-HCl $10 \mathrm{mM}, \mathrm{pH}$ 7.5) / Tween (T: $0.1 \%)$ ] containing milk proteins (5\%) and incubated overnight with the polyclonal rabbit anti-calretinin antibody $(1: 1000 ; 214$ 102, Synaptic Systems, Germany). The membranes were then washed three times in TBS-T for $15 \mathrm{~min}$ and incubated for $45 \mathrm{~min}$ at room temperature with a horseradish peroxidase (HRP)-conjugated secondary antibody (1:2000, ECL donkey anti-rabbit IgG HRP-linked, GE Healthcare, Belgium). The secondary antibody was diluted in TBS-T containing milk proteins (5\%). The membranes were washed in three steps: $15 \mathrm{~min}$ in TBS-T containing milk proteins 5\%, $15 \mathrm{~min}$ in TBS-T, $15 \mathrm{~min}$ in TBS. Calretinin expression was detected by chemiluminescent revelation (SuperSignal ${ }^{\circledR}$ West Pico Chemiluminescent Substrate, Thermo Scientific, Belgium). These experiments were performed at least on 3 different WT and $C R^{-}$ mice and rats.

\subsection{Quantification of acrosome reaction}

The experimental procedure was adapted from a previously described methodology [22]. Spermatozoa were collected in a capacitating medium (gassed modified Krebs-Ringer) and were incubated for at least $30 \mathrm{~min}$ to allow capacitation before the addition of any agent. Acrosomal reaction was induced by the addition of either the calcium ionophore A-23187 $(2 \mu \mathrm{M}$ or $8 \mu \mathrm{M})$, Thapsigargin $(2 \mu \mathrm{M})$ or Progesterone $(5 \mu \mathrm{M}$ or $50 \mu \mathrm{M})$ for $60 \mathrm{~min}$ at $36^{\circ} \mathrm{C}[23]$.

A-23187, Thapsigargin and Progesterone were dissolved in dimethylsulfoxide (DMSO, $0.2 \%$ final concentration), which was also added in control media. After $60 \mathrm{~min}$ incubation in the presence or absence of the stimulating agent (A-23187, Thapsigargin or Progesterone), the spermatozoa were collected and centrifuged at $500 \mathrm{x}$ $\mathrm{g}$ for $5 \mathrm{~min}$ at room temperature. The supernatant was discarded and the sperm pellet re-suspended in PBS and spread on a histological slide with a glass pipette. For each genotype (WT versus $C R^{-/-}$), five slides were prepared both for the stimulated and the control conditions. The slides were dried at room temperature, fixed in cold absolute methanol for $15 \mathrm{~min}$ and rinsed in PBS for $10 \mathrm{~min}$ A labelling with PNA-FITC assessed the presence of the acrosome. A minimum of 500 spermatozoa were analysed in each experimental condition. Individual experiments were repeated 3-6 times with different cell populations.

\subsection{Measurements of motility parameters by computer-assisted sperm analysis}

Sperm motility parameters were analysed by a Computer-Assisted Sperm Analysis (C.A.S.A.) system from Microptic S.L. (Microptic SCA Sperm Class Analyzer 5.4, Spain). The C.A.S.A. system was composed of a digital camera (Basler scA780-54 fc) mounted on a microscope (Nikon Eclipse 50i) equipped with a heated stage $\left(36^{\circ} \mathrm{C}\right)$.

Spermatozoa were collected in a modified Krebs-Ringer HEPES medium ( $\mathrm{NaCl} 94.6 \mathrm{mM}, \mathrm{KCl} 4.78 \mathrm{mM}, \mathrm{MgSO}_{4} 1.19 \mathrm{mM}$, Na Lactate $21.58 \mathrm{mM}$, Na Pyruvate $0.5 \mathrm{mM}, \mathrm{CaCl}_{2} 1.71 \mathrm{mM}, \mathrm{KH}_{2} \mathrm{PO}_{4} 1.19 \mathrm{mM}$, HEPES $20 \mathrm{mM}$, D-glucose $5.56 \mathrm{mM}$, BSA $4 \mathrm{mg} / \mathrm{ml}, \mathrm{pH}$ 6.8). This media is devoid of $\mathrm{HCO}_{3}{ }^{-}$to record sperm motility parameters in non-capacitating conditions. Hyperactivated motility was induced by the addition of $\mathrm{NH}_{4} \mathrm{Cl} 25 \mathrm{mM}$ to spermatozoa incubated in 4-well plates $[24,25]$. An equal volume of medium was used as control condition. For each analysis, sperm samples $(6 \mu \mathrm{l})$ were introduced in a Leja standard count analysis chamber (SC20-01-C, Alere Health, Netherlands). Motility data were collected by 30 frame images at 50 frames/second with a negative phase contrast optic (Ph-). Motility parameters (including VCL - curvilinear velocity, ALH - amplitude of lateral head movement, BCF - beat cross frequency, HYP - hyperactivation) were assessed at $0 \mathrm{~min}$, $10 \mathrm{~min}, 20 \mathrm{~min}, 30 \mathrm{~min}$ and $60 \mathrm{~min}$. The hyperactivation was measured by selecting the percentage of spermatozoa which presented a VCL $>$ $200 \mu \mathrm{m} / \mathrm{s}$ and a straightness $<70 \%$ [10]. A minimum of 150 spermatozoa were analysed at each time point for each condition. Individual experiments were repeated 9 times with different cell populations.

\subsection{Fertility assessment}

The fertility potential of WT and $C R^{-/-}$mice was evaluated by a polygamous mating scheme with one adult male housed together with two adult females. Fertility was assessed by quantification of the number of offsprings from at least 30 breedings for each genotype.

\subsection{Statistical analysis}

Data normality was assessed using the Kolmogorov-Smirnov test. According to this test, the impact of the genotype and of the calcium ionophore A-23187, Thapsigargin or Progesterone on the acrosome reaction were carried out using parametric tests (paired Student's $t$-test or non-paired Student's $t$-test) or non-parametric tests (Mann-Whitney $U$ test or Wilcoxon signed-rank test).

A comparison between $\mathrm{CR}^{-/-}$and WT motility parameters was assessed by using a non-paired Student's $t$-test, one-way ANOVA with repeated measures and two-ways ANOVA with repeated measures. Student's $t$-test was also used in order to assess the difference between $C R^{-/-}$and WT litter sizes.

Statistical analyses were carried out using SPSS software (IBM SPSS Statistics, IBM Corporation). P-value (p) was considered as statistically significant when $\mathrm{p}<0.05$.

\section{Results}

\subsection{Detection of calretinin in murine spermatozoa}

Indirect immunofluorescence revealed a labelling of calretinin in WT mouse and rat spermatozoa incubated with the polyclonal rabbit anti-calretinin antibody (Fig. 1a, c). This staining was not observed when the calretinin antibody was replaced by purified non-immune rabbit immunoglobulins (Fig. 1e, g).

Calretinin staining was observed in the head and the principal piece of the flagellum from WT mouse and rat spermatozoa. The calretinin head labelling appeared to be localised in the acrosomal region in both mouse and rat sperm, as attested by the yellow-coloured overlay of the calretinin marker (red) and PNA-FITC (green) (Fig. 1a, c).

The calretinin labelling was also compared in non-capacitated and capacitated sperm and no difference was observed. Whether in noncapacitated or capacitated sperm, the acrosome staining for calretinin was absent in acrosome-reacted sperm (data not shown).

Cerebellum tissue was used as positive control. An immunostaining for calretinin was observed in the granular layer from WT mouse and rat cerebellum (Fig. 1b, d), mostly in granule cells as previously described [15]. This staining was again completely absent when the calretinin antibody was substituted with non-immune serum (Fig. 1f, h).

The specificity of this labelling was tested using the antibody incubated with the purified calretinin protein. A faint labelling of the WT acrosome was still observed, but the principal piece of the flagellum was not labelled (Supplemental data Fig. S1). Likewise, the staining of the granular layer from WT cerebellum disappeared (Supplemental data Fig. S1).

In the next series of experiments, calretinin immunodetection was performed on spermatozoa and cerebellum from $C R^{-/-}$mice.

Labelling of $C R^{-/-}$spermatozoa with anti-calretinin still revealed a positive staining of the acrosomal region and the principal piece of the 

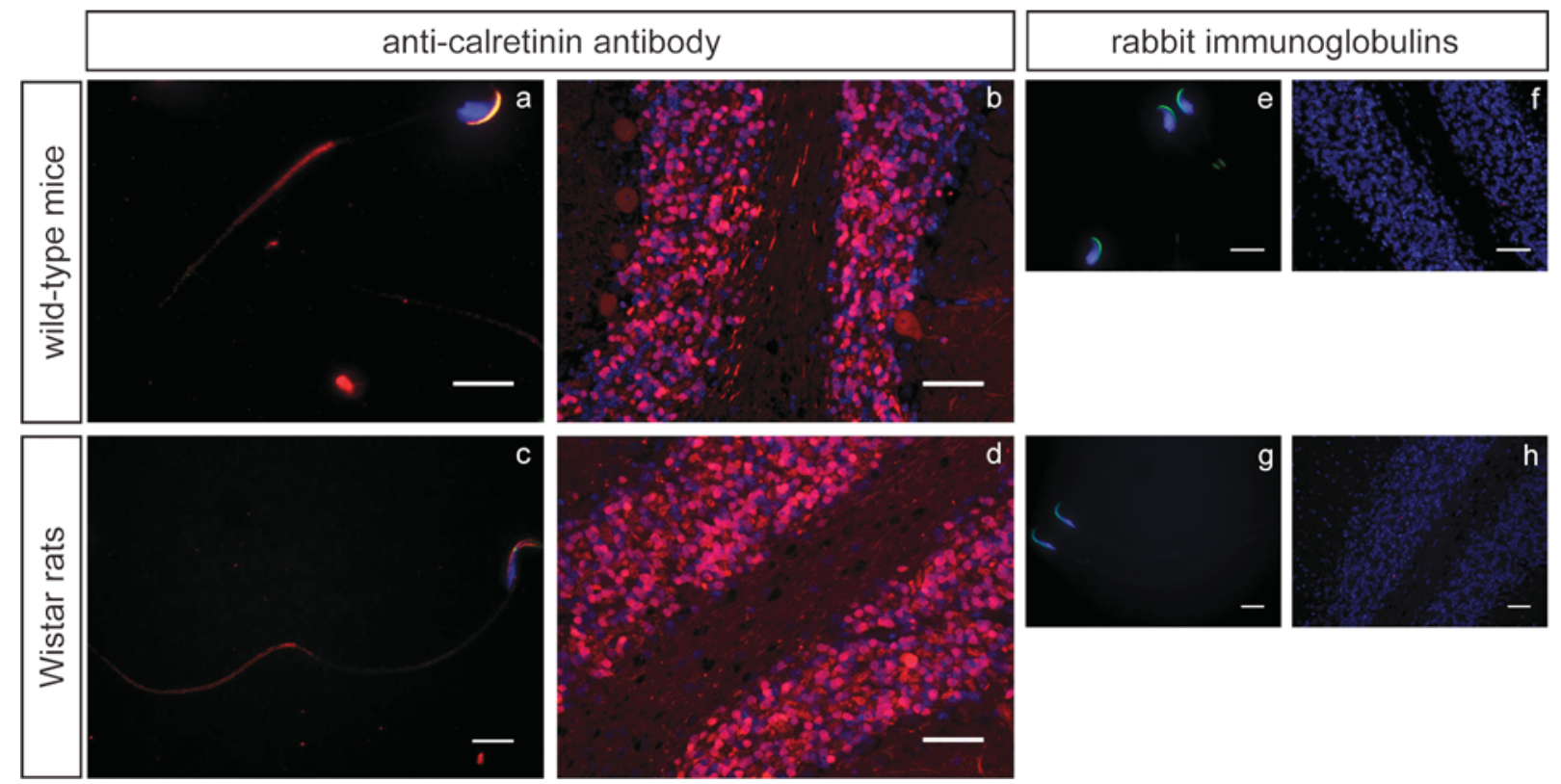

Fig. 1. Calretinin detection (antibody: 214 102, Synaptic Systems) in C57Bl6 (WT) mice and Wistar rats spermatozoa. Detection of calretinin (red) in spermatozoa $(\mathrm{a}, \mathrm{c})$ and cerebellum $(\mathrm{b}, \mathrm{d})$ from WT mice $(\mathrm{a}, \mathrm{b})$ and Wistar rats $(\mathrm{c}, \mathrm{d})$ by indirect immunofluorescence. Negative controls were performed on spermatozoa $(\mathrm{e}, \mathrm{g})$ and cerebellum (f,h) from WT mice (e,f) and Wistar rats (g,h). Overlay images of calretinin (a,c) or rabbit immunoglobulins $(e, g)$ and the acrosome labelled with PNAFITC (green). Nuclei were labelled with DAPI (blue). Scale: $10 \mu \mathrm{m}(\mathrm{a}, \mathrm{c}, \mathrm{e}, \mathrm{g})$ and $50 \mu \mathrm{m}$ (b,d,f,h) (For interpretation of the references to colour in this figure legend, the reader is referred to the web version of this article).

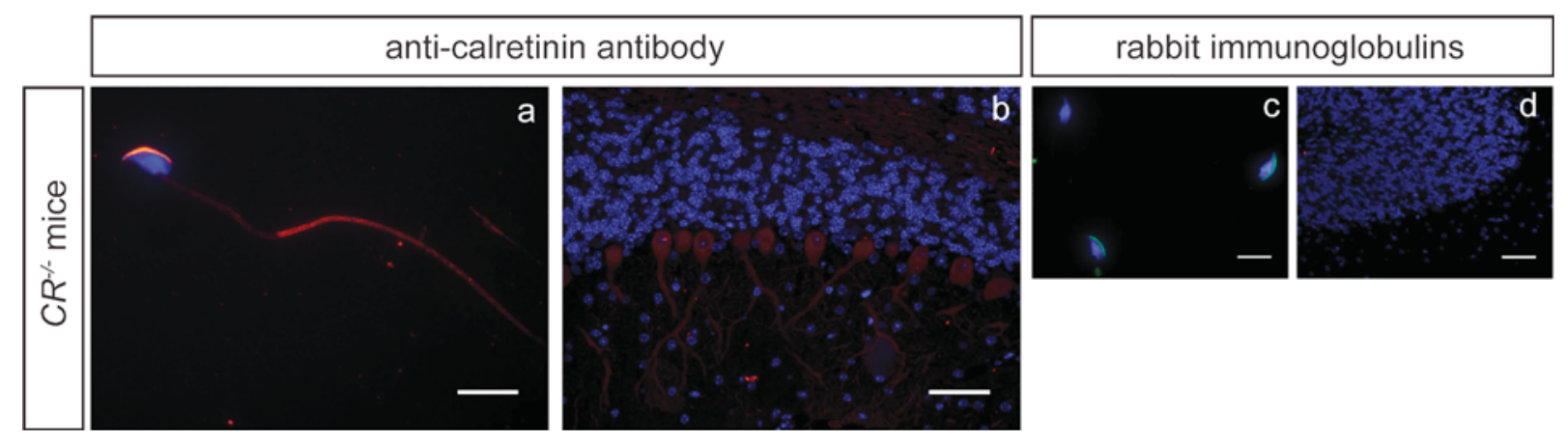

Fig. 2. Labelling of calretinin knockout $\left(C R^{-/-}\right)$spermatozoa with the anti-calretinin antibody (antibody: 214 102, Synaptic Systems). Detection of calretinin (red) in spermatozoa (a) and cerebellum (b) from $C R^{-/}$mice by indirect immunofluorescence. Negative controls were performed on spermatozoa (c) and cerebellum (d) from $\mathrm{CR}^{-1-}$ mice. Overlay images of calretinin (a) or rabbit immunoglobulins (c) and the acrosome labelled with PNA-FITC (green). Nuclei were labelled with DAPI (blue). Scale: $10 \mu \mathrm{m}(\mathrm{a}, \mathrm{c})$ and $50 \mu \mathrm{m}(\mathrm{b}, \mathrm{d})$ (For interpretation of the references to colour in this figure legend, the reader is referred to the web version of this article).

\section{flagellum (Fig. 2a).}

$C R^{-/-}$cerebellum, however, did not display any calretinin staining in the granular layer. As previously reported, a labelling of cerebellum from $C R^{-/-}$mice with anti-calretinin revealed a faint staining of the Purkinje cells, likely the result of a faint cross-reactivity with the closely related EF-hand protein calbindin D-28k (CB); for details see discussion (Fig. 2b) [26]. No staining was detected when purified rabbit immunoglobulins replaced the primary calretinin antibody (Fig. 2c, d).

To detect a potential cross-reactivity between the calretinin antibody and calbindin D-28k, we incubated the antibody with purified calbindin D-28k protein. The remaining labelling of Purkinje cells from $\mathrm{CR}^{-/-}$cerebellum disappeared (Supplemental data Fig. S2a, b). Under identical experimental conditions, the fluorescent signal detected in $C R^{-1-}$ sperm was weakened (Supplemental data Fig. S2c, d). Altogether, these findings suggest cross-reactivity between the calretinin antibody and the calcium-binding protein calbindin D-28k [26].

Lastly, different antibodies produced against calretinin and commercialised by Swant (Supplemental data Fig. S3) and/or Bioprime (Supplemental data Fig. S4) were also tested. Similar stainings, as those described above, were reproduced on spermatozoa as well as on cerebellum from WT and $C R^{-/-}$mice and rats.

\subsection{Expression of calretinin in murine spermatozoa}

To further complete the characterisation of calretinin in sperm cells, Western blotting was performed with protein extracts from WT and $C R^{-/-}$mouse sperm or rat sperm, as well as with rodent cerebellum used as a positive control tissue. A band at a molecular weight of $29 \mathrm{kDa}$ was detected in WT mouse and rat sperm protein extracts (Fig. 3) [17]. A band at the identical position was also observed in WT mouse and rat cerebellum protein extracts (Fig. 3). Such a $29 \mathrm{kDa}$ band was never detected in $C R^{-/-}$sperm and $C R^{-/-}$cerebellum protein extracts. In both cerebellar samples (mouse WT and rat) a slightly smaller protein was weakly stained; the position of this band coincides with calbindin D-28k, the closest relative of calretinin within the EF-hand family. A band at this position was also detected in $C R^{-/-}$sperm extracts, hinting towards the presence of calbindin D-28k in $C R^{-/-}$sperm extracts [16]. 


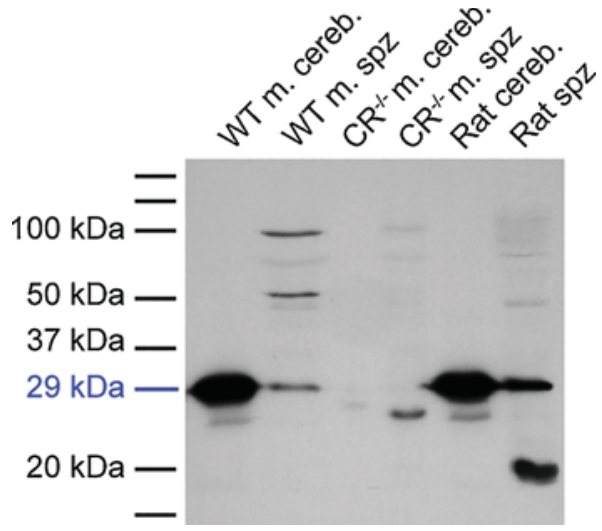

Fig. 3. Expression of calretinin in C57Bl6 (WT) mice, calretinin knockout $\left(C R^{-/-}\right)$mice and Wistar rats spermatozoa. Western blot analysis of calretinin $(29 \mathrm{kDa})$ expression in sperm protein extracts (spz) from WT and $C R^{-/-}$mice (m.) and rats. Cerebellum (cereb.) extracts from WT mice, $C R^{-1-}$ mice and rats were used as control tissues. Anti-calretinin antibody: 214 102, Synaptic Systems.

\subsection{Quantification of the acrosome reaction in $W T$ and $C R^{-/-}$mice}

The quantification of the acrosome reaction was assessed in mouse spermatozoa incubated in the absence or presence of a simulating agent: either the $\mathrm{Ca}^{2+}$ ionophore A-23187, Thapsigargin or Progesterone.

After a $60 \mathrm{~min}$ incubation period in basal conditions, the percentage of acrosome-reacted sperm averaged to $23.61 \pm 1.97 \%$ in WT mice $(\mathrm{n}=15)$ and $25.14 \pm 3.02 \%$ in $C R^{-/-}$mice $(\mathrm{n}=16)(\mathrm{p}>0.05)$ (data not shown).

The addition of increasing concentrations of the $\mathrm{Ca}^{2+}$ ionophore A23187 to the incubation media provoked concentration-dependent increases in the acrosome reaction, both in WT and $C R^{-/-}$sperm (Fig. 4a, b). In WT control spermatozoa, incubation with $2 \mu \mathrm{M}$ (Fig. 4a) and $8 \mu \mathrm{M}$ (Fig. 4b) A-23187 for 60 min resulted in a $28.32 \pm 11.79 \%$ and a $58.22 \pm 3.15 \%$ increase in the acrosome reaction, respectively ( $\mathrm{p}>0.05 ; \mathrm{p}<0.05$ ). Likewise, in $C R^{-/-}$spermatozoa, the addition of $2 \mu \mathrm{M}$ (Fig. 4a) and $8 \mu \mathrm{M}$ (Fig. 4b) A-23187 provoked a $28.45 \pm 14.16 \%$ and a $50.61 \pm 2.27 \%$ increase in the acrosome reaction, respectively ( $\mathrm{p}>0.05$; $\mathrm{p}<0.05$ ). At both A-23187 concentrations tested, the stimulatory effect of the $\mathrm{Ca}^{2+}$ ionophore on the acrosome reaction was indistinguishable in WT and $C R^{-1-}$ sperma-

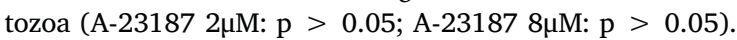

The addition of Thapsigargin $(2 \mu \mathrm{M})$ to the incubation medium resulted in an $14.77 \pm 6.70 \%$ and an $8.27 \pm 2.39 \%$ increase in the acrosome reaction in WT and $C R^{-/-}$sperm, respectively (Fig. 4c) ( $\mathrm{p}>0.05$ ). As observed for the $\mathrm{Ca}^{2+}$ ionophore, the effect of Thapsigargin was identical in both genotypes (Fig. 4c) ( $p>0.05)$.

Moreover, in WT control spermatozoa, the addition of $5 \mu \mathrm{M}$ or $50 \mu \mathrm{M}$ of the more physiological agent Progesterone induced an $6.83 \pm 0.85 \%$ and an $11.24 \pm 0.67 \%$ stimulatory effect on the acrosome reaction, respectively (Fig. 4d) ( $\mathrm{p}<0.05$; $\mathrm{p}<0.01$ ). In $C R^{-/-}$ sperm, and under identical experimental conditions, $5 \mu \mathrm{M}$ Progesterone provoked an $8.52 \pm 2.61 \%$ increase whilst $50 \mu \mathrm{M}$ Progesterone evoked an $9.75 \pm 0.77 \%$ increase in the acrosome reaction (Fig. 4d) ( $p<0.05 ; p<0.001$ ). The amplitude of the stimulatory responses to Progesterone was, again, similar in both genotypes $(\mathrm{p}>0.05$ in both cases).

\subsection{Measurements of sperm motility in WT and $C R^{-/-}$mice}

C.A.S.A. measurements were performed in order to compare WT to $C R^{-/-}$mice sperm motility parameters under different experimental conditions. The curvilinear velocity (VCL), the amplitude of lateral head movement (ALH) and the beat cross frequency (BCF) are illustrated in Fig. 5.

In basal conditions, i.e. in the absence of any stimulating agent, $C R^{-/-}$sperm initially moved at a lower speed (VCL, Fig. 5a) and with a shorter head movement (ALH, Fig. 5b) than the WT sperm. The curvilinear velocity was reduced at the time point $0 \mathrm{~min}(\mathrm{p}<0.05)$ and the amplitude of lateral head movement was shortened at time $0 \mathrm{~min}$ (p $<0.05)$ in $C R^{-/-}$mice compared to WT mice. Under such basal experimental conditions, however, the beat cross frequency in $C R^{-/-}$ sperm was comparable to that recorded in WT spermatozoa ( $p>0.05$ ) (Fig. 5c)

In the next series of experiments, sperm motility hyperactivation was stimulated by incubating WT and $C R^{-/-}$mouse spermatozoa in the presence of millimolar concentrations of $\mathrm{NH}_{4} \mathrm{Cl}$ [27]. The addition of $25 \mathrm{mM} \mathrm{NH}_{4} \mathrm{Cl}$ to the incubation medium induced a sustained increase both in the curvilinear velocity $(\mathrm{p}<0.001)$ and in the amplitude of lateral head movement ( $\mathrm{p}<0.001$ ) (Fig. 5a, b). By contrast, the intracellular alkalinisation mediated by the addition of $\mathrm{NH}_{4} \mathrm{Cl}$ [27] led to a sustained decrease in the beat cross frequency ( $p<0.001$ ) (Fig. 5c). The hyperactivation percentage increased after the addition of $25 \mathrm{mM}$ of $\mathrm{NH}_{4} \mathrm{Cl}(\mathrm{p}<0.01)$ (Fig. $5 \mathrm{~d}$ ). These effects of $\mathrm{NH}_{4} \mathrm{Cl}$ were observed for both genotypes, but appeared to be weakened in $C R^{-/-}$spermatozoa (Fig. 5). Statistical analysis (one-way ANOVA) of C.A.S.A. measurements indicated that the $\mathrm{NH}_{4} \mathrm{Cl}$-induced increases in curvilinear velocity, lateral head movement and hyperactivation percentage were not significantly different in WT and $C R^{-/-}$sperm (p $>0.05$, respectively). Likewise, the magnitude of the $\mathrm{NH}_{4} \mathrm{Cl}$-induced reduction in beat cross frequency tended to be less pronounced in $C R^{-/-}$than in WT mouse spermatozoa; yet the apparent differences failed to reach statistical significance ( $\mathrm{p}>0.05$ ) (Fig. 5c).

However, two-way analysis of variance with repeated measures revealed an inter-subject effect of the genotype on the beat cross frequency ( $p<0.05$ ), although this feature was not observed for the curvilinear velocity, the amplitude of the lateral head movement and the percentage of hyperactivated sperm ( $\mathrm{p}>0.05$, respectively).

Incidentally, the putative impact of a rise in the extracellular osmolarity was tested by the addition of $25 \mathrm{mM}$ and $50 \mathrm{mM}$ sucrose to the incubation medium. The sucrose-induced increases in osmolarity did not affect sperm motility parameters (data not shown).

\subsection{Assessment of fertility in WT and $C R^{-/-}$mice}

The WT litter sizes averaged $6.6 \pm 0.43$ offspring per litter $(36 \mathrm{WT}$ breedings) (Fig. 6). By contrast, the $C R^{-/-}$litter sizes were reduced compared to the WT litter sizes. The number of pups averaged $2.7 \pm 0.42$ per litter for $C R^{-/-}$mice $\left(30 \mathrm{CR}^{-/-}\right.$breedings $)$ (p $<0.001)$ (Fig. 6).

\section{Discussion}

The present study revealed the presence and expression of the EFhand calcium-binding protein calretinin in rodent spermatozoa. To the best of our knowledge, such a protein has never been detected in spermatozoa or male immature germ cells either from rodent or other species.

Calretinin was characterized in mouse and rat spermatozoa by indirect immunofluorescence. The protein was localized in the acrosomal region and the principal piece of the flagellum both in mouse and rat spermatozoa. Competition studies of the antibody with the calretinin protein suggested a non-specific staining of the acrosomal region but a specific calretinin labelling of the principal piece of the flagellum. Within the granule cell layer of WT mouse and rat cerebellum, serving as positive control cells, calretinin staining in granule cells appeared rather homogenous throughout the soma and neuropil as expected for a protein mostly considered as a cytosolic one. Western blot experiments were performed and confirmed the expression of calretinin, a $29 \mathrm{kDa}$ 
A

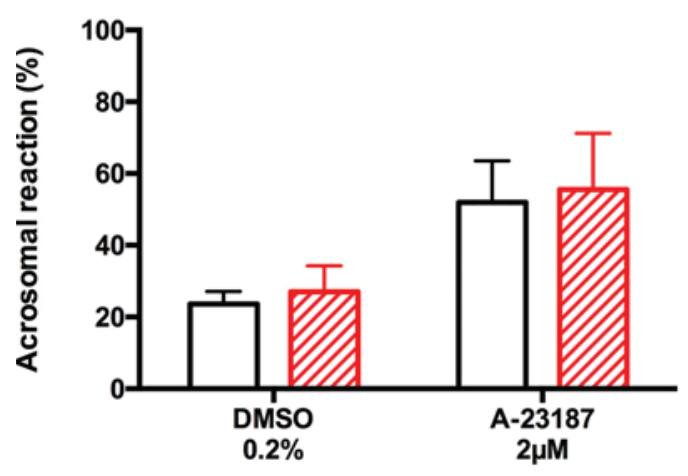

C

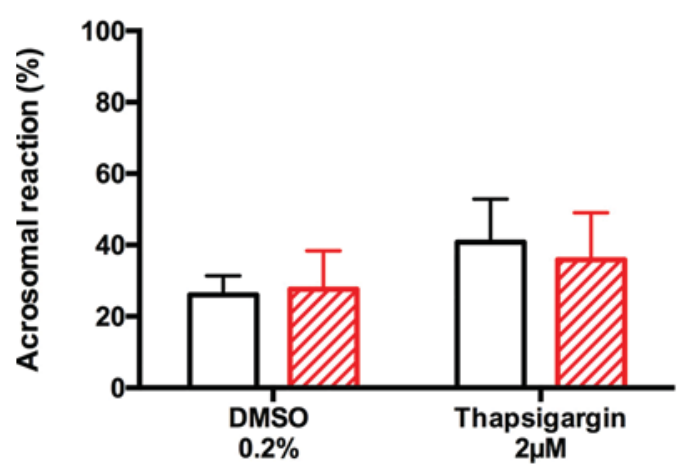

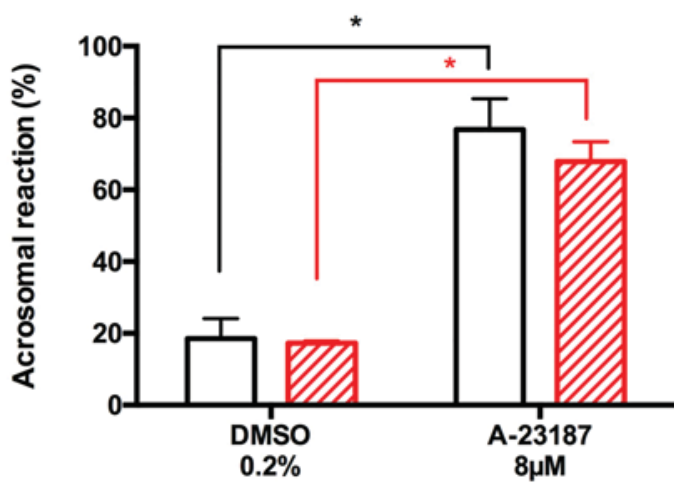

D

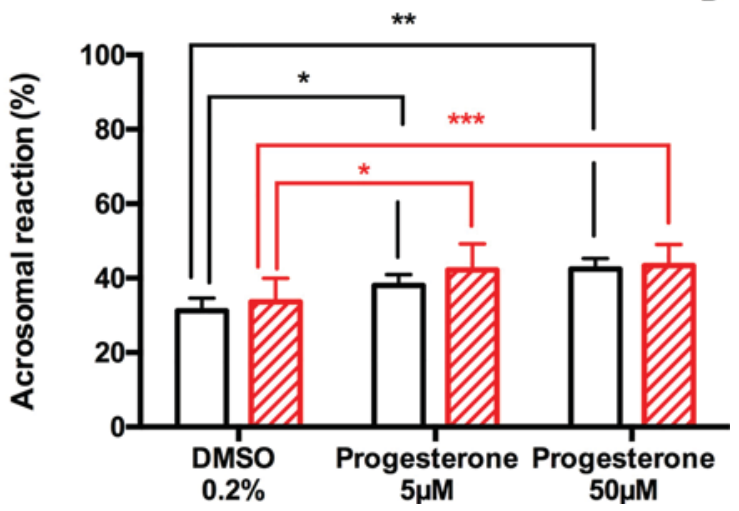

Fig. 4. Quantification of acrosome reaction from C57Bl6 (WT) and calretinin knockout $\left(\mathrm{CR}^{-/-}\right)$spermatozoa. The acrosome reaction was induced by the addition of

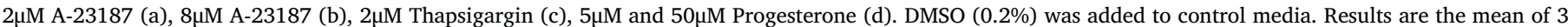
$\left(\mathrm{a}, \mathrm{c}, \mathrm{d}_{\mathrm{WT}}\right), 4\left(\mathrm{~d}_{\mathrm{CR}-/}\right)$ or 6 (b) individual experiments. Error bars refer to S.E.M. ${ }^{*} \mathrm{p}<0.05$; ${ }^{* *} \mathrm{p}<0.01 ;{ }^{* * *} \mathrm{p}<0.001$.

protein [17], in protein extracts from WT mouse and rat sperm.

Immunodetection studies were also conducted on calretinin knockout $\left(C R^{-/-}\right)$mice. Indirect immunofluorescence still revealed a staining on $C R^{-/-}$spermatozoa incubated in the presence of the anticalretinin antibody. The localization and intensity of the labelling was roughly similar to that observed in WT sperm. Although no calretinin immunoreactivity was detected in cells of the $C R^{-/-}$granule cell layer, a faint staining was also noticed in Purkinje cells from $C R^{-/-}$cerebellum. These initially unexpected results were reproduced with the different anti-calretinin antibodies tested and have been previously ascribed in the cerebellum to the detection of calbindin-D28k, the closest relative of calretinin within the EF-hand calcium-binding protein family and highly expressed in Purkinje cells [26]. Labelling of the flagellum principal piece in $C R^{-/-}$sperm could be, in a similar way, associated with the detection of calbindin D-28k, as suggested by our competition studies with the purified calbindin D-28k protein. This detection might be further enhanced by an upregulation of calbindinD28k when the calretinin gene is inactivated. The absence of calretinin expression in $\mathrm{CR}^{-/-}$spermatozoa and $\mathrm{CR}^{-/-}$cerebellum was evidenced by Western blot analysis. A weaker signal at approximately $27 \mathrm{kDa}$ was detected, supporting the hypothesis that the anti-calretinin antibody probably cross-reacted with calbindin D-28k or another closely related protein in $\mathrm{CR}^{-/-}$spermatozoa.

In order to evaluate the role of calretinin in sperm calcium-dependent physiological processes, we evaluated the acrosomal reaction and motility parameters in WT and $\mathrm{CR}^{-1-}$ mice spermatozoa. Previous studies suggested the involvement of other calcium-binding proteins, such as calmodulin, calcineurin and calreticulin in the modulation of sperm motility and exocytosis of acrosomal enzymes [8,10,12,28-30].
Our experimental data indicated that the lack of calretinin expression in mouse spermatozoa did not affect the percentage of acrosomereacted sperm under basal experimental conditions. Moreover, the acrosome reactions induced by the calcium ionophore A-23187, Thapsigargin or Progesterone were of identical magnitude, independently whether the experiments were conducted with WT or $C R^{-/-}$spermatozoa. Such findings, however, do not fully exclude a potential involvement of calcium-binding proteins in the physiological modulation of the acrosome response.

Incidentally, the concentration-dependent effects recorded in A23187-stimulated mouse sperm further emphasized the importance of the magnitude of calcium inflow in the "induced" acrosome reaction [22,31].

Motility parameters, such as the lateral head movement (ALH), the curvilinear velocity (VCL), the beat cross frequency (BCF) and the percentage of hyperactivated sperm were also assessed in WT and $C R^{-}$

spermatozoa. The "in vitro" measurements performed under basal non-stimulatory incubating conditions revealed an obvious reduction in the amplitude of the lateral head movement as well as in the curvilinear velocity in $\mathrm{CR}^{-/-}$sperm. As expected, the incubation of WT spermatozoa in the presence of $\mathrm{NH}_{4} \mathrm{Cl}$ induced hyperactivation [24,25]. Such a dynamic response appeared to be slightly reduced in $\mathrm{CR}^{-1-}$ spermatozoa. Likewise, the $\mathrm{NH}_{4} \mathrm{Cl}$-induced decrease in $\mathrm{BCF}$ was less marked in $C R^{-/-}$spermatozoa. Taking into account these dynamic observations, the association between the alterations in motility parameters and the $60 \%$ reduction in $C R^{-/-}$litter size, as observed in the present study, needs to be further evaluated.

Calcium is a key second messenger in sperm physiology. Changes in its intracellular concentration regulate numerous physiological 


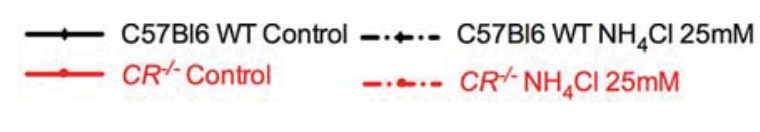

A

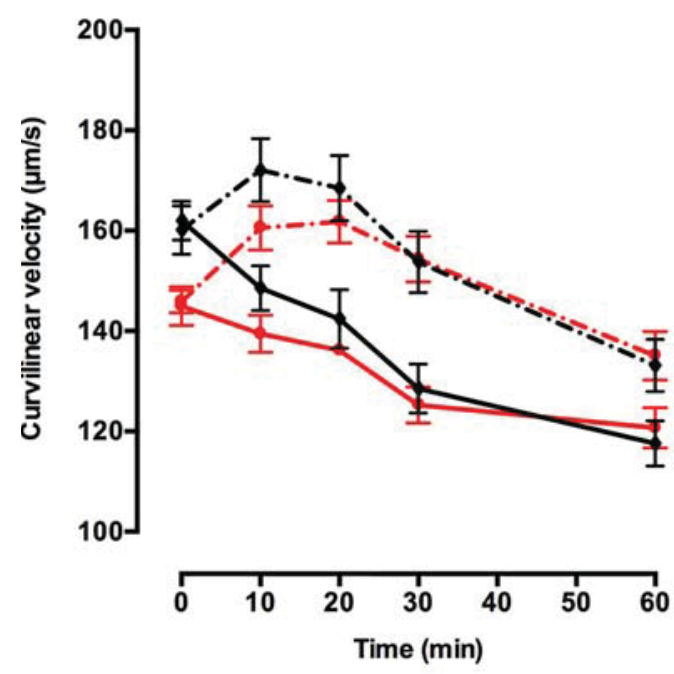

C

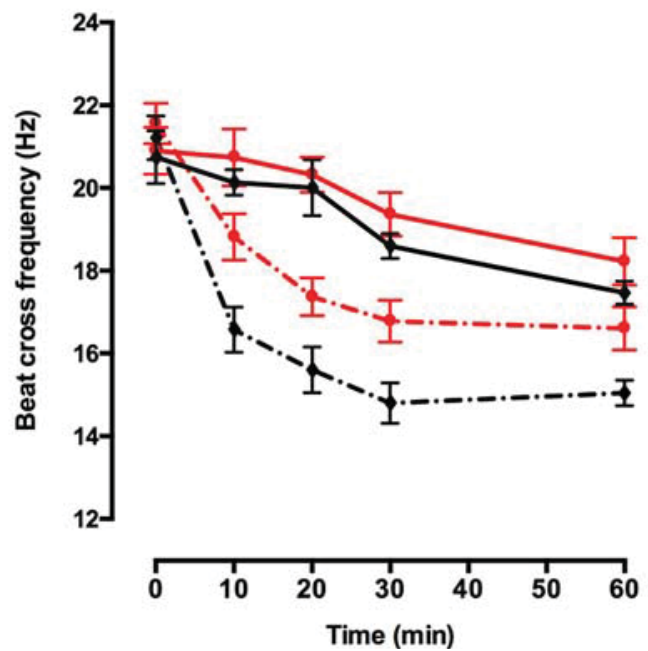

B

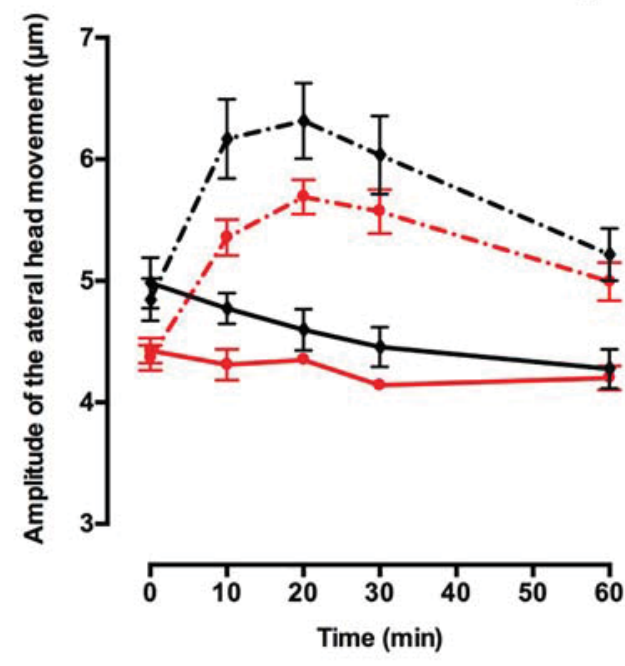

D

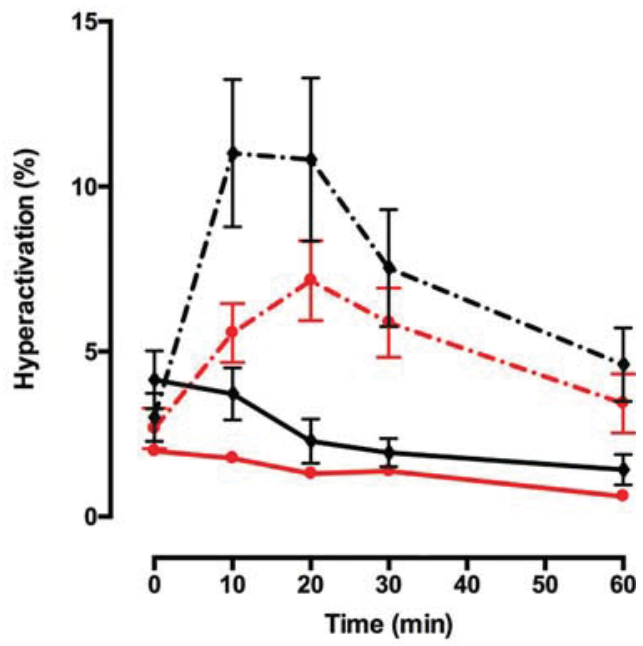

Fig. 5. Measurements of motility parameters in C57Bl6 (WT) and calretinin knockout $\left(C R^{-/-}\right)$spermatozoa. Assessment by C.A.S.A. of the curvilinear velocity (VCL, a), the lateral head movement (ALH, b), the beat cross frequency (BCF, c) and the percentage of hyperactivated sperm (HYP, d) from WT and $C R^{-1-}$ spermatozoa. Results are the mean of 9 individual experiments. Error bars refer to S.E.M.

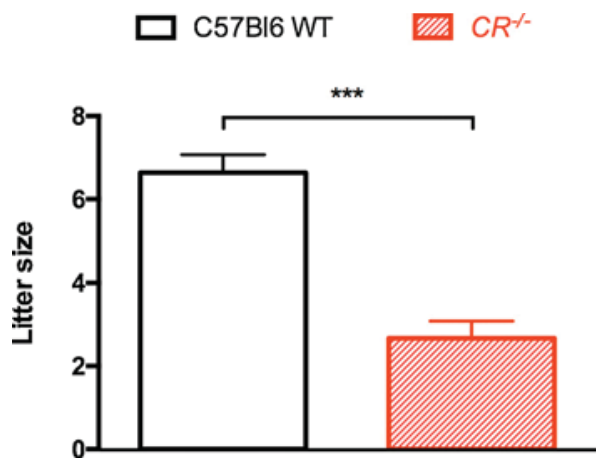

Fig. 6. Assessment of fertility in C57Bl6 (WT) and calretinin knockout $\left(\mathrm{CR}^{-/-}\right)$ mice. Number of offspring per litter obtained from WT and $C R^{-/-}$mice. Results are the mean of $36 \mathrm{WT}$ and $30 \mathrm{CR}^{-/-}$breedings. Error bars refer to S.E.M. $* * * \mathrm{p}<0.001$. processes essential to sperm fertility such as capacitation, modification in the pattern of motility and acrosome reaction. A precise timing and localization is essential in the signaling cascade leading to fertilization. Calcium signaling domains have recently been evidenced in the principal piece of mouse spermatozoa [9]. Calretinin and other proteins from the EF-hand calcium binding family could be involved in the spatio-temporal fine-tuning of the calcium-signaling cascade through a "buffering" of calcium ions in these calcium domains or a direct interaction with effector proteins. Binding of $\mathrm{Ca}^{2+}$ to the EF-hand domain of calcium-binding proteins might indeed modify their interaction with target proteins or the cytoskeleton and trigger a calcium sensor activity such as capacitation-associated protein phosphorylation [28,30,32]. Further assessment of calretinin's spatial distribution and the possible participation of calcium-binding proteins in calcium microdomains might allow to precisely determining their roles in sperm calcium signaling. 


\section{Conclusions}

In conclusion, our study provides the first evidence for the presence and expression of calretinin in rodent sperm. Functional studies further suggest a possible role of calretinin in the control of sperm motility and modulation of male fertility. These findings introduce a novel actor in the relatively limited family of calcium-binding proteins described in spermatozoa. Additional "in vitro" and "in vivo" investigations need to be conducted in order to define the precise roles of EF-hand calciumbinding proteins in sperm physiology.

\section{Conflict of interest}

The authors declare that they have no conflict of interest.

\section{Ethical approval}

All applicable international, national, and/or institutional guidelines for the care and use of animals were followed. This article does not contain any studies with human participants performed by any of the authors.

\section{Acknowledgements}

We thank E. Hupkens for mice genotyping.

This study was supported by a "Fund for Research Training in Industry and Agriculture" grant from the Belgian National Fund for Scientific Research (F.R.S.-F.N.R.S.), a grant from the David and Alice Van Buuren fundings completed by the Jaumotte-Demoulin institution, and a grant from the Swiss National Science Foundation (SNSF \# 31003A_130680) to B.S.

\section{Appendix A. Supplementary data}

Supplementary material related to this article can be found

\section{References}

[1] H.M. Florman, R.A. Fissore, Chapter 4 - fertilization in mammals, in: T.M. Plant, A.J. Zeleznik (Eds.), Knobil and Neill's Physiology of Reproduction, 4th ed., Academic Press, San Diego, 2015pp. 149-196.

[2] B. Robaire, B.T. Hinton, Chapter 17-the epididymis, Knobil and Neill's Physiology of Reproduction, 4th ed., Academic Press, San Diego, 2015 pp. 691-771. https:// www.sciencedirect.com/science/article/pii/B978012397175300017X . (Accessed 21 November 2017).

[3] A. Abou-haila, D.R.P. Tulsiani, Signal transduction pathways that regulate sperm capacitation and the acrosome reaction, Arch. Biochem. Biophys. 485 (2009) 72-81, http://dx.doi.org/10.1016/j.abb.2009.02.003.

[4] B.M. Gadella, P.E. Visconti, Regulation of capacitation, in: C. Barratt, C.J. De Jonge (Eds.), The Sperm Cell: Production, Maturation, Fertilization, Regeneration, Cambridge University Press, Cambridge, 2006pp. 134-169 https://www. cambridge.org/core/books/sperm-cell/regulation-of-capacitation/ DADECC7D856EDB9923AE6ED7818F523D.

[5] M.R. Miller, S.A. Mansell, S.A. Meyers, P.V. Lishko, Flagellar ion channels of sperm similarities and differences between species, Cell Calcium 58 (2015) 105-113, http://dx.doi.org/10.1016/j.ceca.2014.10.009.

[6] A. Gallo, E. Tosti, Ion currents involved in gamete physiology, Int. J. Dev. Biol. 59 (2015) 261-270, http://dx.doi.org/10.1387/ijdb.150202et.

[7] S.B. Herrick, D.L. Schweissinger, S.-W. Kim, K.R. Bayan, S. Mann, R.A. Cardullo, The acrosomal vesicle of mouse sperm is a calcium store, J. Cell. Physiol. 202 (2005) 663-671, http://dx.doi.org/10.1002/jcp.20172.

[8] H.-C. Ho, S.S. Suarez, Characterization of the intracellular calcium store at the base of the sperm flagellum that regulates hyperactivated motility, Biol. Reprod. 68 (2003) 1590-1596, http://dx.doi.org/10.1095/biolreprod.102.011320.

[9] J.-J. Chung, S.-H. Shim, R.A. Everley, S.P. Gygi, X. Zhuang, D.E. Clapham,
Structurally distinct $\mathrm{Ca}(2+)$ signaling domains of sperm flagella orchestrate tyrosine phosphorylation and motility, Cell 157 (2014) 808-822, http://dx.doi.org/ 10.1016/j.cell.2014.02.056.

[10] Y. Si, P. Olds-Clarke, Evidence for the involvement of calmodulin in mouse sperm capacitation, Biol. Reprod. 62 (2000) 1231-1239.

[11] J. Castillo Bennett, C.M. Roggero, F.E. Mancifesta, L.S. Mayorga, Calcineurinmediated dephosphorylation of synaptotagmin VI is necessary for acrosomal exocytosis, J. Biol. Chem. 285 (2010) 26269-26278, http://dx.doi.org/10.1074/jbc. M109.095752.

[12] H. Miyata, Y. Satouh, D. Mashiko, M. Muto, K. Nozawa, K. Shiba, Y. Fujihara A. Isotani, K. Inaba, M. Ikawa, Sperm calcineurin inhibition prevents mouse fertility with implications for male contraceptive, Science 350 (2015) 442-445, http://dx. doi.org/10.1126/science.aad0836.

[13] B. Bar-Shira Maymon, H. Yavetz, L. Yogev, S.E. Kleiman, B. Lifschitz-Mercer, L. Schreiber, A. Botchan, R. Hauser, G. Paz, Detection of calretinin expression in abnormal immature Sertoli cells in non-obstructive azoospermia, Acta Histochem. 107 (2005) 105-112, http://dx.doi.org/10.1016/j.acthis.2005.02.002.

[14] Z.A. Radi, D.L. Miller, Immunohistochemical expression of calretinin in canine testicular tumours and normal canine testicular tissue, Res. Vet. Sci. 79 (2005) 125-129, http://dx.doi.org/10.1016/j.rvsc.2004.11.016.

[15] A. Lewit-Bentley, S. Réty, EF-hand calcium-binding proteins, Curr. Opin. Struct Biol. 10 (2000) 637-643.

[16] B. Schwaller, The continuing disappearance of "pure" Ca2 + buffers, Cell. Mol. Life Sci. 66 (2009) 275-300, http://dx.doi.org/10.1007/s00018-008-8564-6.

[17] B. Schwaller, M. Meyer, S. Schiffmann, "New" functions for "old" proteins: the role of the calcium-binding proteins calbindin D-28k, calretinin and parvalbumin, in cerebellar physiology. Studies with knockout mice, Cerebellum 1 (2002) 241-258, http://dx.doi.org/10.1080/147342202320883551.

[18] B. Schwaller, Calretinin: from a "simple" $\mathrm{Ca}(2+)$ buffer to a multifunctional protein implicated in many biological processes, Front. Neuroanat. 8 (2014) 3, http://dx. doi.org/10.3389/fnana.2014.00003.

[19] S. Schurmans, S.N. Schiffmann, H. Gurden, M. Lemaire, H.P. Lipp, V. Schwam, R. Pochet, A. Imperato, G.A. Böhme, M. Parmentier, Impaired long-term potentiation induction in dentate gyrus of calretinin-deficient mice, Proc. Natl. Acad. Sci. U. S. A. 94 (1997) 10415-10420.

[20] U.K. Laemmli, Cleavage of structural proteins during the assembly of the head of bacteriophage T4, Nature 227 (1970) 680-685.

[21] L.S. Minamide, J.R. Bamburg, A filter paper dye-binding assay for quantitative determination of protein without interference from reducing agents or detergents, Anal. Biochem. 190 (1990) 66-70.

[22] P. Lybaert, A. Danguy, F. Leleux, S. Meuris, P. Lebrun, Improved methodology for the detection and quantification of the acrosome reaction in mouse spermatozoa, Histol. Histopathol. 24 (2009) 999-1007.

[23] C.J. De Jonge, C.L.R. Barratt, Methods for the assessment of sperm capacitation and acrosome reaction excluding the sperm penetration assay, Methods Mol. Biol. 927 (2013) 113-118, http://dx.doi.org/10.1007/978-1-62703-038-0 11.

[24] B. Marquez, G. Ignotz, S.S. Suarez, Contributions of extracellular and intracellular $\mathrm{Ca} 2+$ to regulation of sperm motility: release of intracellular stores can hyperactivate CatSper1 and CatSper2 null sperm, Dev. Biol. 303 (2007) 214-221, http:// dx.doi.org/10.1016/j.ydbio.2006.11.007.

[25] S.C. Loux, K.R. Crawford, N.H. Ing, L González-Fernández, B. Macías-García, C.C. Love, D.D. Varner, I.C. Velez, Y.H. Choi, K. Hinrichs, CatSper and the relationship of hyperactivated motility to intracellular calcium and $\mathrm{pH}$ kinetics in equine sperm, Biol. Reprod. 89 (2013) 123, http://dx.doi.org/10.1095/biolreprod. 113.111708 .

[26] S.N. Schiffmann, G. Cheron, A. Lohof, P. d'Alcantara, M. Meyer, M. Parmentier, S. Schurmans, Impaired motor coordination and Purkinje cell excitability in mice lacking calretinin, Proc. Natl. Acad. Sci. U. S. A. 96 (1999) 5257-5262.

[27] W. Alasmari, C.L.R. Barratt, S.J. Publicover, K.M. Whalley, E. Foster, V. Kay, S. Martins da Silva, S.K. Oxenham, The clinical significance of calcium-signalling pathways mediating human sperm hyperactivation, Hum. Reprod. 28 (2013) 866-876, http://dx.doi.org/10.1093/humrep/des467.

[28] W.M. Wasco, R.L. Kincaid, G.A. Orr, Identification and characterization of calmodulin-binding proteins in mammalian sperm flagella, J. Biol. Chem. 264 (1989) 5104-5111.

[29] S.S. Suarez, Control of hyperactivation in sperm, Hum. Reprod. Update 14 (2008) 647-657, http://dx.doi.org/10.1093/humupd/dmn029.

[30] F.A. Navarrete, F.A. García-Vázquez, A. Alvau, J. Escoffier, D. Krapf, C. SánchezCárdenas, A.M. Salicioni, A. Darszon, P.E. Visconti, Biphasic role of calcium in mouse sperm capacitation signaling pathways, J. Cell. Physiol. 230 (2015) 1758-1769, http://dx.doi.org/10.1002/jcp.24873.

[31] H. Tateno, D. Krapf, T. Hino, C. Sánchez-Cárdenas, A. Darszon, R. Yanagimachi, P.E. Visconti, Ca2 + ionophore A23187 can make mouse spermatozoa capable of fertilizing in vitro without activation of cAMP-dependent phosphorylation pathways, Proc. Natl. Acad. Sci. U. S. A. 110 (2013) 18543-18548, http://dx.doi.org/ 10.1073/pnas.1317113110.

[32] D.E. Clapham, Calcium signaling, Cell 131 (2007) 1047-1058, http://dx.doi.org/ 10.1016/j.cell.2007.11.028. 